\title{
A representação das mulheres acusadas de introduzir cédulas falsas na imprensa do Rio de Janeiro durante a Primeira República (1889-1930)
}

The representation of women accused of introducing false banknotes in the press in Rio de Janeiro during the First Republic (1889-1930)

La representación de las mujeres acusadas de introducir billetes falsos en la prensa de Río de Janeiro mientras la Primera República (1889-1930)

\begin{abstract}
Resumo
Neste artigo é analisado a representação das mulheres acusadas de introduzir cédulas falsas na imprensa do Rio de Janeiro durante a Primeira República(1889-1930). Com esse objetivo ele utilizará como exemplo o caso de Quitéria de Jesus devido a sua ampla repercussão pública e seu resultado em 1909. Como fonte principal, são utilizadas matérias do crime retiradas de alguns periódicos que são intercruzadas com outras fontes complementares, como o relatório do Ministro da Justiça e Negócios Interiores de 1909. Através deles, tentaremos mostrar como a cobertura sobre o caso levantou concepções de gênero que impactaram a sua sentença criminal e marcaram a forma com que essas criminosas foram retratadas no meio jornalístico.

Palavras-chave: Processos criminais; Falsificação de dinheiro; Inquéritos policiais; Mulheres; Quitéria de Jesus.

Abstract

This article analyzes the representation of women accused of introducing false banknotes in the press in Rio de Janeiro during the First Republic (1889-1930). For this purpose, he will use the case of Quiteria de Jesus as an example due to its wide public repercussion and its result in 1909. As the main source, crime stories taken from some periodicals are used and are intersected with other complementary sources, such as the report of the Minister of Justice and Interior Affairs of 1909. Through them, we will try to show how the coverage of the case raised gender conceptions that impacted their criminal sentence and marked the way in which these criminals were portrayed in the journalistic milieu.
\end{abstract}

Keywords: Criminal proceedings; Counterfeiting money; Police inquiries; Women; Quitéria de Jesus.

\section{Resumen}

Este artículo analiza la representación de las mujeres acusadas de introducir billetes falsos en la prensa de Río de Janeiro mientras la Primera República (1889-1930). Con ese objetivo, él utilizará como ejemplo el caso de Quitéria de Jesus por su amplia repercusión pública y su resultado en 1909. El informe del Ministro de Justicia e Interior de 1909. Através de ellos, intentaremos mostrar cómo la cobertura del caso planteó concepciones de género que impactaron su condena penal y marcaron la forma en que estas delincuentes fueron retratadas en los círculos periodísticos.

Palabras clave: Procedimientos criminales; Falsificación de dinero; Investigaciones policiales; Mujeres; Quitéria de Jesus.

\section{Introdução}

Segundo o sumário crime, auto que consta a acusação do delito, em maio de 1909, apresentou-se um indivíduo ao $23^{\circ}$ distrito policial, correspondente à área de Irajá, alegando ter recebido três cédulas falsas. Duas delas, teriam sido recebidas por seus funcionários em data imprecisa, mas a terceira foi recebida pelo seu cliente Cornelio Elias de Quitéria de Jesus. Por sua vez, ela declarou que quem havia passado o dinheiro foi Manoel José dos Santos, seu marido (Arquivo da Justiça Federal, 1909). Conforme afirma um jornal local (A Capital,1909), durante o inquérito, foi feita uma inspeção na casa do casal por um 
grupo de agentes. Nesse local foi encontrado um punhado de notas falsas "bem-feitas" embaixo da cama. Embora conste no processo, que ambos foram acusados pelo crime de introduzi-las em circulação, apenas foi mencionado pela matéria que Quitéria foi presa em flagrante. Sua detenção foi mantida em segredo por Ataliba Corrêa Dutra, delegado distrital responsável pelo caso, para melhor encaminhar as diligências, mas a notícia se espalhou, quando o juiz permitiu a sua pronúncia.

Era comum haver periódicos cobrindo delitos de falsificação de dinheiro como o relatado acima devido às novas demandas do público naquela época. Conforme afirma Ottoni (2012), desde a década de 1880, a imprensa passava por importantes inovações na área de comunicação, transporte e impressão. Com a melhora da produção e distribuição dos jornais, surgiram os primeiros conglomerados de mídia. A competição entre editoras criou diferentes colunas especializadas, dentre elas, aquelas relacionadas a crimes. A partir dessa nova demanda, houve a necessidade de ter pessoas dedicadas a cada assunto aparecendo a categoria dos repórteres policiais. Apesar da sua pretensão a imparcialidade, a leitura desses profissionais sobre os eventos era orientada pelos seus próprios interesses e convicções políticas. Escrever sobre uma matéria importante poderia levar os seus autores à fama, a uma futura promoção e também servia para construir a opinião pública sobre a criminalidade. Ao serem publicadas diariamente pelos jornalistas, essas notícias naturalizavam a ideia de que as transgressões penais faziam parte da vida cotidiana do Rio de Janeiro.

Dentre os delitos que ocorriam no Distrito Federal, vale chamar atenção para a falsificação de dinheiro. Uma matéria do jornal O Século, encontrada durante o levantamento da pesquisa, afirmava que a derrama de cédulas falsas no Rio de Janeiro cresceu "extraordinariamente". Nas três delegacias auxiliares, "tem sido incessante o trabalho para ter a terminação dos inquéritos" (Século, 1909). Mesmo com esforços instaurados pela polícia, a maioria das investigações, terminavam arquivadas aumentando o prejuízo do comércio e da população.

Esse maior aparecimento de casos envolvendo moeda falsa é atribuído ao contexto histórico. Segundo Bretas (1997), com a proclamação da República em 1889, o Rio de Janeiro se tornava centro administrativo e político do país devendo como sua capital representá-lo no exterior. Desde 1870, ele sofria um rápido crescimento populacional devido à abolição da escravidão e à imigração trazendo novos desafios para o seu funcionamento. Naquele momento, também, a elite intelectual brasileira sofria com o impacto do pensamento científico positivista que defendia a modernização do país levando a intervenção do governo no espaço carioca.

Nesse sentido uma das medidas tomadas pelos governantes na capital federal, a fim de organizá-la, foi a regulamentação do comércio. Segundo a autora Amy Chackel (2014), instituir a cobrança de novas taxas e autorizações, para os comerciantes, era uma forma de adquirir uma outra fonte de contribuição. Estruturalmente, também auxiliava a fiscalização da circulação de mercadorias naquele espaço. A partir dessas novas diretrizes adotadas, fomentou-se a formação de todo um mercado ilegal. Nem vendedores e nem consumidores podiam adquirir necessidades materiais da vida seguindo os impostos criados instituídos. O que os levava a realizar diversas práticas para suprir essa demanda por dinheiro, como não se registrar no governo municipal, vender bilhetes de loteria ou falsificar dinheiro.

Apesar do caso Quitéria de Jesus ser mais uma ocorrência dessa onda de criminalidade apontada no cenário carioca, ele possuía um diferencial. Após um levantamento dos processos judiciários no Arquivo da Justiça Federal do Rio de Janeiro, foi identificado 1233 inquéritos referentes a crimes de moeda falsa que chegaram em diferentes varas da Justiça Federal durante a Primeira República. Essa amostragem revela que apenas uma pequena parcela de 84 casos, cerca de $7 \%$, tinham mulheres como réus demonstrando uma predominância masculina na autoria desses crimes. Dentre eles, a maioria das acusações terminavam arquivadas, cerca de $63 \%$, por falta de elementos que comprovassem a culpa delas.

Embora a fraca presença nas estatísticas criminais, a preocupação com criminalidade feminina era, de acordo com Bretas, recorrente durante todo o século XIX e início do XX, "fazendo parte da nova criminologia positivista presente" no regime republicano. Essa ideologia "tentava confinar as mulheres a um papel mais familiar, cientificamente apoiado em bases 
biológicas" (Bretas,1997). Nesse sentido o objetivo desse artigo é compreender como essas criminosas eram representadas na imprensa carioca no período republicano. O caso da Quitéria foi selecionado como recorte porque ele foi um dos poucos que levaram a uma condenação, ainda que temporária, teve grande repercussão pública e também levantou concepções de gênero, que impactavam a forma com que as mulheres, acusadas de introduzir notas falsas, eram retratadas nos jornais.

\section{Metodologia}

Para a análise do seu objeto esse artigo utilizou prioritariamente a metodologia qualitativa. Conforme afirma Mussi, Assunção e Nunes (2019), a pesquisa qualitativa busca interpretar realidades a partir da compreensão dos casos concretos e de suas particularidades do seu contexto. Em um primeiro momento contudo, foi necessário realizar um levantamento das mulheres envolvidas com falsificação de dinheiro para chegar ao seu tema. Nesse sentido, a partir de uma consulta ao Arquivo da Justiça Federal no Rio de Janeiro, em São Cristóvão, realizamos uma amostra dos processos crimes envolvendo falsificação de dinheiro entre 1890 e 1930. As informações registradas nos autos permitiram criar uma base de dados com a nacionalidade, idade, nome, profissão e endereço dos acusados. Em seguida, esses elementos foram utilizados para achar mais detalhes sobre o caso de cada criminosa na Hemeroteca Digital. Dessa pesquisa minuciosa, o caso Quitéria de Jesus chamou atenção em relação a sua sentença criminal, sua repercussão e ao seu resultado. A partir dele, foram analisados os questionamentos enfrentados pelas mulheres, acusadas de introduzir notas falsas pela imprensa. No intuito de complementar aquilo que foi encontrado, também foi consultado o relatório do Esmeraldino Olímpio Torres Bandeira, Ministro da Justiça e dos Negócios Interiores, em 1909.

\section{Resultados e Discussão}

Como foi afirmado, Quitéria de Jesus foi presa, em maio de 1909, durante uma inspeção feita por um corpo de agentes do $23^{\circ}$ distrito à sua casa. No início do século XX, a polícia carioca passou por importantes mudanças tentando acompanhar as transformações estruturais que ocorriam na cidade. Diante dessas questões, o governo republicano, imbuído da ideologia positivista, realizou uma série de transformações no seu serviço policial buscando a profissionalização e a especialização da sua atuação de modo a conter possíveis novos perigos que surgissem.

A reforma que será abordada por esse artigo é a de 1907 feita pelo chefe de polícia Alfredo Pinto. Ela ainda estava vigente quando as notas falsas foram encontradas na casa de Quitéria de Jesus em 1909. Nesse novo modelo, segundo o artigo cinco do regulamento do serviço policial do Distrito Federal, o Rio de Janeiro passava a ser dividido em 28 distritos policiais qualificados em 3 entrâncias e três delegacias auxiliares (Decreto n.6440, 1907).

O cargo mais alto dentro da hierarquia policial era o de chefe de polícia, responsável pela sua direção. Para ocupar essa posição, era necessário, de acordo com o artigo nove, ser nomeado pelo Presidente da República, "ser doutor ou bacharel em Direito em alguma faculdade nacional, com dez anos, pelo menos, de tirocínio na magistratura, advocacia ou administração pública" (Decreto n.6440, 1907). Apesar da importância dessa função, havia uma alta rotatividade de pessoas, que a utilizavam para adquirir mais contatos políticos e entrar na carreira jurídica (Bretas, 2019).

As delegacias auxiliares eram subordinadas diretamente ao chefe de polícia devendo cooperar com ele no policiamento da cidade. Seus delegados deveriam ser formados em Direito e possuir quatro anos de experiência em advocacia, magistratura ou administração pública. Além dos encargos comuns as três delegacias, cada uma terá o seu dever específico. A Primeira Delegacia Auxiliar de acordo com o artigo trinta e quatro, "era responsável por manter e regularizar o fluxo do trânsito, inspecionar escolas e colônias correcionais e as delegacias distritais de terceira entrância” (Decreto n.6440, 1907). 
A Segunda Delegacia Auxiliar se encarregava de outras particularidades do Rio de Janeiro. Ela inspecionava de acordo com o artigo trinta quatro, "divertimentos públicos e casas de empréstimos além de fiscalizar delegacias de segunda entrância" (Decreto n.6440, 1907). Por último, existe a Terceira Delegacia Auxiliar que estava voltada, de acordo com o artigo trinta e três da mesma legislação, para a área portuária sendo incumbida de todas diligências de crimes a bordo de navios e também fiscalizar delegacias de primeira entrância.

Cada uma das delegacias auxiliares devia supervisionar um distrito policial. Os delegados distritais também eram profissionais formados em direito com, pelo menos, dois anos de prática forense. Uma das suas principais responsabilidades era a instauração do inquérito. No caso da falsificação de dinheiro, por ser de acordo com o artigo trinta e três, um crime da competência da Justiça Federal, a investigação deveria ser encaminhada para o delegado auxiliar não só pela questão do delito, como também para que fizessem diligências periciais, que dependiam da autorização da Repartição Central (Decreto n.6440, 1907).

Os periódicos da época não falam quem fez a denúncia do crime de Quitéria apenas, que a acusação foi corroborada pelo encontro de cédulas falsas na sua casa levando-a a ser presa em flagrante. Como afirmado anteriormente, seu inquérito começou sendo dirigido por Ataliba Correa Dutra, delegado do $23^{\circ}$ distrito policial, que deve ter feito as primeiras diligências como o auto de apreensão, o recolhimento dos depoimentos das testemunhas e o envio das cédulas para a análise da Caixa de Amortização, entidade responsável pelo papel-moeda. Em seguida, o caso foi provavelmente encaminhado para a Terceira Delegacia Auxiliar, onde ficaria sob a responsabilidade de Jorge de Gomes Martos, delegado da época, que poderia requisitar mais dados e exames sobre o crime a fim de comprovar a culpa da acusada. Uma vez terminado o inquérito, ele seria mandado para um juiz substituto da vara criminal, que avaliaria, se existe ou não um caso, e depois, os acusados seriam julgados pelo juiz Godofredo Cunha.

Segundo o jornal O País, no final do processo criminal, apenas Quitéria de Jesus foi condenada a 4 anos de prisão na Casa de Detenção do Distrito Federal, por introduzir cédulas falsas em circulação (O País,1909). No seu artigo vinte e seis, a lei determinava que o cárcere só poderia ocorrer em crimes inafiançáveis, como é o da falsificação de moeda, se houvesse indícios da autoria dos réus, como era o caso da acusada (Lei n 1785,1909). Apesar de condenada, sua sentença criminal seria mais tarde revisada, de acordo com um novo decreto, que sairia naquele mesmo ano, para três anos e quatro meses (Decreto n.2110, 1909). Essa mudança ocorreu pois a nova legislação poderia ser aplicada, de acordo com o "se estipulasse uma punição menos rigorosa" (Código Penal,1890).

O caso de Quitéria de Jesus se destaca na época porque, como foi afirmado, constituía-se em um dos poucos em que o inquérito se encerrava com a ré presa. $\mathrm{O}$ que acabou contribuindo para ele se amplamente discutido pela imprensa. A maioria das investigações terminavam arquivadas sendo um assunto amplamente discutido por periódicos da época como o (Jornal do Brasil,1910) e (O Século,1910). Eles atribuíam essa impunidade ora ao despreparo da polícia, a influência política do meio e a benevolência das leis e do judiciário.

Outra questão que dificultava a prisão desses criminosos era a natureza dessa infração penal. Segundo Galeano(2019), a falsificação de dinheiro envolvia redes delitivas que conectavam diferentes figuras: o produtor, que era quem fabricava as cédulas falsas, geralmente um fotógrafo ou litógrafo imigrante que operava fora do país. Depois existiam os intermediários, que ajudavam atravessar esse material pela fronteira. Por último, os circuladores buscavam passá-las em pequenas quantidades, nas transações econômicas cotidianas. Quando fazia suas operações, a polícia capturava, na maioria das vezes, os últimos elos da cadeira, como foi o caso de Quitéria, porque os membros do grupo não se conheciam sendo raro chegar aos fabricantes.

Um dos motivos, que talvez tenham causado a repercussão pública do caso de Quitéria, é que ele apresenta uma ruptura na forma em que é representado pela imprensa, antes e depois do seu cárcere. No momento da investigação, é possível observar que, em mais de um periódico, é ressaltado o fato dela ser mulher e envolvida com falsificação de dinheiro nos títulos 
das matérias: "Até mulheres", "Uma falsária", "uma mulher que passa notas falsas”(A Capital, 1909; Gazeta de Notícias, 1909; A Notícia,1909). Além da questão informativa aparente de resumir o assunto para os seus leitores, eles demonstravam a importância atribuída ao gênero pelos seus autores. Essa impressão desses diferentes profissionais está ligada ao próprio contexto histórico. Como foi afirmado, a maioria dos crimes ligados a falsificação de dinheiro, que aconteceram em 1889 e 1930, tinha como autores homens, sendo incomum a participação feminina.

No periódico A Capital, um jornalista chega a afirmar sobre o caso que "fica registrada a primeira falsária, e, oxalá, não tenhamos de registrar outras" (A Capital, 1909). O que reforça de maneira literal esse fenômeno atípico nesse tipo de delito, apesar de não ser o primeiro caso registrado no Rio de Janeiro entre final do século XIX e início do XX como menciona o autor.

Também vale chamar atenção nesse primeiro momento para a forma que o caso Quitéria de Jesus foi registrado por uma matéria do jornal A Notícia. Nessa reportagem o autor descreve que a acusada "a par de saber engomar, cozinhar, lavar e fazer outros serviços domésticos, sabia também introduzir na circulação notas falsas" (A Notícia,1909). Para além da questão de ser ou não essa a profissão da acusada, essa fala do jornalista é significativa porque deixa implícito a impressão de que a ré tinha uma dupla natureza: do lar e criminosa. Essa interpretação está ligada às mudanças na forma de se pensar o papel da mulher durante o período republicano.

Naquela época, a figura feminina passava por importantes transformações. Segundo Araújo (1993) que analisa a cidade e a família no Rio de Janeiro no início do século XX, uma dessas mudanças era o estímulo a sua entrada no mercado de trabalho. Com a diminuição do espaço urbano residencial, houve um encarecimento do custo de vida na cidade fazendo com que algumas mulheres tivessem que começar a trabalhar, principalmente no setor secundário e terciário. A dinâmica crescente comercial do Distrito Federal também impulsionava esse processo. O regime republicano expandiu o setor público gerando mais empregos na capital. Os avanços tecnológicos também eliminavam as desvantagens do elemento feminino em relação à força física. Dessa forma sua participação profissional torna-se cada vez maior, apesar de circunscrita a uma função de subordinação ao chefe masculino que a coloca à margem de qualquer processo decisório.

Outro fenômeno pela qual a mulher passava era a sua socialização no cenário público. Depois da reforma do prefeito Pereira Passos que ocorreu entre 1903 e 1906, a cidade ganhou novos ares com a abertura de avenidas, praças e a construção de edifícios tornando-se mais atrativa para as famílias usufruírem o seu espaço. Aumenta-se a demanda por novas formas de diversão estimulando com que eventos fossem promovidos como bailes, festas e espetáculos. Conforme afirma Araújo (1993) O Rio de Janeiro sofria com a abertura cinemas, teatros, óperas, circos, cafés, clubes e confeitarias que vinham muitas vezes do exterior para atender a públicos diversos.

Esse processo transformou o estilo de vida carioca, principalmente, do sexo feminino. Enquanto as mulheres pobres já frequentavam o espaço público no seu cotidiano para trabalhar, a mulher de elite, impelida a ficar em casa, busca aos poucos a rua para o seu momento de lazer. O surgimento do bonde e do automóvel serviu-lhe como um grande aliado nesse processo aumentando o seu grau de locomoção na cidade. Diante dessa nova realidade, era necessário que os dirigentes construíssem uma representação simbólica da mulher republicana de modo a protegê-la dos vícios do mundo externo.

Imbuídos desse objetivo, eles se voltam para a ideologia positivista vinda da Europa. Ela tinha como principal representante e um dos fundadores dessa corrente: Cesare Lombroso, considerado um dos responsáveis por fazer desse conhecimento uma ciência.

Segundo Rachel Soihet no seu trabalho sobre a condição das mulheres pobres nesse período, a partir da observação do comportamento de vários animais, esse intelectual determinou que fora algumas exceções, os machos em regra eram superiores as fêmeas. Por serem mais fortes, eles as obrigavam a satisfazer o desejo cabendo depois, a mãe cuidar dos filhotes. Dessa forma a mulher também era similar em comportamento a natureza selvagem por razões naturais devendo ficar em casa e zelar 
a criação dos filhos. Por ficar no âmbito doméstico, ela seria mais fraca e menos inteligente precisando ser tutelada(Soihet, 1997).

Desde a Colônia, a figura feminina tinha como função gerar e cuidar dos seus descendentes não sendo uma questão nova na história brasileira. A diferença é que na República, para além de cumprir essa suposta função natural, ser mãe também carregava o dever de formar os futuros cidadãos moral e socialmente. Os médicos, se utilizando das ideias de Lombroso, passaram a defender que a mulher devia restringir a sua atuação ao lar. Ao introduzir notas falsas em circulação, Quitéria de Jesus vai de encontro com esse modelo idealizado de mulher, motivo pelo qual na reportagem do jornal A Notícia é evidenciado a sua dupla natureza: ser dona de casa e criminosa.

Em comparação ao período anterior, o tempo em que Quitéria de Jesus ficou presa na Casa de Detenção foi mais coberto pela imprensa do que o seu inquérito em si. O principal responsável por esse fenômeno foi o Jornal do Comércio, que enviou um jornalista deles a esse estabelecimento para documentar o que ocorria lá.

Conforme afirma Bretas no seu capítulo sobre a história das prisões no Rio de Janeiro, o interesse do público nas instituições carcerárias é antigo, remetendo a época em que as punições eram interpretadas como um espetáculo. "Neste contexto, o aprisionamento criou ambiguidade e desconfiança. Ao esconder o prisioneiro e privar o público do exercício visível da Justiça" (Bretas, 1909) despertando a curiosidade das pessoas sobre esse espaço. Na República, ao ir para a prisão, o repórter, além de se utilizar desse "ambiente desconhecido" para satisfazer o interesse do público, também aproximava o leitor dos seus residentes demonstrando "coexistência de duas cidades, povoadas por dois tipos diferentes, mas aparentemente similares, de espécies, uma de cidadãos e outra de criminosos" (Bretas, 1909).

Como as reportagens criminais não são assinadas, não foi possível encontrar a identidade do seu autor. Conforme descreve o jornalista no Jornal do Comércio, apesar da Casa de Detenção abrigar "os autores dos mais terríveis crimes", reinava "a mais perfeita ordem e o mais rigoroso asseio" no lugar (Jornal do Comércio, 1910). Na parte das mulheres contudo, causou "surpresa a existência de uma criança de colo muito alva e gorda, de cabelos louros e olhos azuis. Ela era filha de Quitéria de Jesus retratada por ele como "vítima do amor que tem ao seu homem" sendo "capaz de tudo mas nunca de fabricar moeda falsa, trabalho para que é preciso um pouco de engenho e arte" (Jornal do Comércio, 1910).

É significativo observar como a forma que essa criminosa foi retratada mudou consideravelmente entre o jornal A Notícia e o Jornal do Comércio. Enquanto no primeiro periódico, era enfatizado como ela rompia com a imagem típica da mulher republicana, no segundo, ela era retratada como uma mãe, vítima da sua falta de intelecto e do amor que tinha ao seu marido

Antes de compreender essa nova visão apresentada sobre o caso da Quitéria de Jesus, é necessário entender melhor o ambiente da Casa de Detenção do Rio de Janeiro. Para esse estabelecimento, eram destinados, de acordo com o artigo um, "todos os presos legalmente enviados pelas autoridades policiais, administrativas e judiciárias" do Rio de Janeiro (Decreto n.6863,1908). Conforme afirma a autora Amy Chazkel, que estudou sobre esse ambiente, esse estabelecimento surgiu em 1856, no primeiro raio das instalações da Casa de Correção, de modo temporário, em substituição a prisão do Aljube, que remontava ao século XVIII. Naquela época, seu objetivo era deter a circulação pessoas consideradas perigosas para o regime. Com a promulgação da República em 1889, novas infrações foram reconhecidas, como por exemplo, as contravenções, práticas anteriores informalmente punidas tais como jogo, prostituição, comércio ambulante sem licença e vadiagem. Esta nova categoria contudo, "possuía definições desses comportamentos, sempre vagas, e que conferiam um poder extraordinário para aqueles encarregados de fazer valer a lei no cotidiano (...) ocasionando um aumento do número de presos dessa instituição" (Chazkel, 2017).

Mesmo o governo republicano adotando um novo princípio de recuperação do detento, através do trabalho e das colônias penais agrícolas e correcionais, não se conseguia colocar em prática, segundo intelectuais da época, as novas ideias 
sobre cárcere, tais como a instalação de oficinas, a segregação de presos à noite e o seu isolamento durante o dia. Era frequente a preocupação de intelectuais com as consequências que poderiam trazer o contato entre diferentes modalidades de criminosos. Para além disso, também era apontada a questão da falta de espaço nos estabelecimentos carcerários que não conseguiam acompanhar o ritmo das prisões e das condenações.

Na Casa de Detenção do Rio de Janeiro, a situação era precária. Sua população carcerária era composta por três perfis. Primeiro, existiam aquelas pessoas que estavam aguardando ali o resultado das suas sentenças no sistema penal. Segundo, aqueles que cumpriam penas curtas informalmente. Por fim, a maior categoria era composta por indivíduos que esperavam os seus julgamentos. Também recebiam, de forma extraoficial, todos aqueles que precisavam de assistência pública e não conseguiam encontrar em outras instituições (Chazkel,2017). Dessa forma pode-se observar que como esse órgão era consequência da disputa de poder nas ruas travadas pela polícia e do caráter vago da lei servindo até de abrigo para os mais necessitados.

Os mais vulneráveis, os pobres, negros e desempregados, a ação da polícia constituíam maioria da população carcerária da Casa de Detenção (Chazkel, 2017). Havia uma divisão social no seu interior que privilegiava as pessoas de maior status em detrimento das classes mais baixas. Direitos como os de sair da cela para receber as visitas e comer alimentos vindos de fora da cadeia eram reservados apenas para alguns. O que mostra que eram ambientes que na sua composição reproduziam as desigualdades socioeconômicas do exterior.

Segundo o relatório do Ministro da Justiça e dos Negócios interiores Esmeraldino Olímpio Torres Bandeira, referente aos anos de 1909 e 1910, nesse estabelecimento possuía uma dependência exclusiva para as criminosas. Nesse local "possuíam 80 reclusas, as quais, sob a direção de uma senhora para isso contratada, costuram e lavam todas as roupas" dos presos do estabelecimento, dos internos do Asilo de Menores Abandonados, do Gabinete Médico Legal e outras dependências da polícia (Bandeira, 1909). O que se percebe, ao analisar o documento, é que nem todas as mulheres cabiam nesse espaço pois, só em 1909 entraram 666 detentas. O que leva a concluir que essas presas deviam ficar misturadas com os homens contrariando o que foi previsto no seu regulamento.

Conforme afirma Bruna Angotti sobre o surgimento dos presídios femininos, apesar de haver normas em algumas instituições que exijam essa divisão, ela só ocorria se de acordo com os seus administradores e as condições físicas para tal. Até a década de 40, não havia nenhuma diretriz legal em âmbito nacional que exigisse prisões separadas conforme os sexos (Angotti, 2018). Dessa forma é possível observar que no momento da visita do jornalista, Quitéria de Jesus provavelmente se encontrava em um espaço superlotado e sem estrutura contrariando a visão de ordem e asseio descrita por ele na matéria.

Não é especificado na reportagem, mas talvez tenha sido nesse lugar, que ela tenha dado a luz a seu filho. Apesar de ser um ambiente que abriga menores abandonados, a criança de Quitéria de Jesus parece ter chamado a atenção do repórter que a descreve como alva, loira e de olhos azuis contrariando o perfil da maioria dos presos. Naquela época, como afirma Luciano Goés na sua obra sobre o saber jurídico naquele tempo, a ideologia positivista, acreditava que a história da humanidade era organizada em uma escala evolutiva que começava em um ancestral comum vindo da África e terminava nas sociedades brancas europeias. À medida que alguns homens se afastavam dessa origem, eles iam deixando de lado sua primitividade, associada ao povo negro, sofrendo um processo de clareamento de pele e de desenvolvimento significativo das suas condições físicas, psíquicas e morais. Mesmo sofrendo esse "aperfeiçoamento", a carga genética selvagem inicial se mantinha presente entre esses homens em escalas distintas, sendo exclusivamente perigosa na raça negra (Goés, 2015). Enquanto no homem branco a razão superaria esses instintos primitivos, isso não ocorreria no negro devido a sua impulsividade. Dessa forma o fato de Quitéria de Jesus ter dado luz a uma criança com uma aparência física europeizada que viveria o resto da sua pena no ambiente criminoso pode ter sido um dos fatores que despertou a condescendência do jornalista para o caso 
Research, Society and Development, v. 10, n. 8, e36610817357, 2021

(CC BY 4.0) | ISSN 2525-3409 | DOI: http://dx.doi.org/10.33448/rsd-v10i8.17357

Outro fator que possivelmente tenha contribuído para essa mudança da representação de Quitéria de Jesus é a forma que as criminosas eram pensadas na ideologia positivista, adotada pela elite brasileira. Em relação a esse assunto Lombroso, seu principal representante, entendia que a criminalidade era identificada, a partir de sinais anatômicos que mostravam quais indivíduos estariam destinados hereditariamente a transgredir a lei. Uma vez que a mulher era vista como inferior ao homem e pertencente a esfera do lar, quanto mais ela tivesse caraterísticas que fugissem a essa natureza, mais degenerada ela era.

O jornal A notícia era um periódico de menor e estrutura repercussão em comparação ao jornal do Comércio, mas é possível observar que a sua matéria estava em consonância com a forma de pensar da época. Quitéria de Jesus foi retratada por eles como se tivesse uma dupla natureza, do lar e criminosa. Dessa forma ela não se encaixa no modelo ideal de mulher republicana sendo dever da polícia discipliná-la através da sua prisão.

Por outro lado, o jornal do Comércio também é influenciado pelo positivismo, mas adotando um viés diferente. Segundo Soihet(1989), Lombroso chegou a criar categorias para classificar a delinquência feminina. A pior delas era a das criminosas natas, consideradas mais raras de serem encontradas e a forma mais perversa de delinquência feminina, caracterizadas pela falta de amor materno, forte erotização, inteligência aguda, veste viris e tendência a uma vida aventureira e ociosa A mais comum eram as criminosas de ocasião, mulheres que possuíam tendência para o delito, mas que precisavam ser incentivadas por outro ou colocadas "em condições de existências tais, que fizessem surgir o fundo de imoralidade". Apesar de não estar explícito no artigo as ideias de Lombroso, é possível identificar sua influência na matéria. No caso de Quitéria de Jesus por ser casada, ter um filho e "sem intelecto" é levada por outro a cometer o crime

Nesse sentido o olhar do repórter do Jornal do Comércio revela como a criminologia positivista subestimava a figura feminina em relação as suas capacidades físicas, morais e biológicas. Por causa da sua suposta maternidade, docilidade e vulnerabilidade, não era dado ao seu universo o direito à violência, já que a prática criminal pelo sexo feminino escandalizava, devido à semelhança que demonstrava com os homens. Seguindo essa concepção, para o jornalista, Quitéria era incapaz de cometer esse crime por ser uma mulher apaixonada e não ter instrução, ainda que a sua acusação fosse de introduzir uma nota falsa em circulação.

Essa visão do repórter está em consonância com uma postura mais conservadora que esse jornal tinha. Esse periódico de acordo com um verbete do CPDOC (Centro de Pesquisa e Documentação de História Contemporânea do Brasil) sobre o mesmo, foi fundado em 1827 por um tipógrafo Pierre François René Plancher. Naquela época, ele acabou se destacando por um discurso de cunho político em relação a imprensa oficial da época. Durante o período republicano, ele sofre uma reforma significativa na sua feição empresarial devido aos novos anseios públicos e ao seu novo dirigente, José Carlos Rodrigues que assumiu em 1890, tornando-se uma das cinco folhas mais importantes da cidade.

Segundo Marialva Barbosa no seu livro sobre a imprensa brasileira entre 1900-2000, seu conteúdo fica mais abrangente, mas não sofre grandes modificações continuando a ser voltado para a classe dirigente. Conforme afirma a autora, ele era "lido por pelos políticos, pelos homens de negócio e funcionários graduados" (Barbosa,2010). Em relação as suas matérias, ele não valorizava “os dramas cotidianos, os crimes passionais e as tragédias diárias". Nesse sentido, apesar do crime de Quitéria de Jesus fugir da proposta do que era frequentemente publicado, seu caso foi acompanhado porque refletia as ideias que influenciavam a elite intelectual da época.

Sem contar que denunciar uma suposta injustiça cometida pelo sistema policial e judiciário era uma notícia que vendia jornal. Como foi falado, os jornalistas escolhem determinados eventos para cobrir porque possuem seus próprios interesses, obter uma promoção, adquirir fama ou como ocorreu nesse caso, construir a ideia de criminalidade feminina no Rio de Janeiro.

A campanha para a liberdade de Quitéria de Jesus iniciada pelo Jornal do Comércio acabou chegando aos altos escalões do governo levando mais tarde o caso ao Esmeraldino Brandão, ministro da Justiça e Negócios Interiores de 1909. No apelo do periódico enviado a ele, reafirmavam a ideia de que ela era vítima do seu analfabetismo, do medo do seu companheiro 
sofrer alguma penalidade e também do nervosismo de estar diante de uma autoridade policial como o doutor Corrêa Dutra. Mediante a repercussão, essa autoridade requisitou ao juiz do caso, Godofredo Cunha, que enviasse mais informações do inquérito, a fim de verificar a possibilidade de um indulto presidencial. Esse recurso visava, de acordo com um jurista da época, "antes a equidade, é um ato de mera caridade oficial, que deixando integralmente substituir a sentença de condenação, só tem por efeito a remissão total ou parcial, da pena imposta" (O Século, 1910).Antes de receber maiores dados sobre o caso, o presidente da república na época, Nilo Peçanha, acabou indultando a criminosa sem consultar o Supremo Tribunal Federal, órgão que julgou seu caso.

\section{Considerações Finais}

A República inaugurou um período de importantes mudanças no Brasil. As cidades vivenciavam um crescimento demográfico devido à vinda de imigrantes estrangeiros e a vinda de escravos libertos, egressos da zona rural. Para se diferenciar de um passado imperial considerado atrasado, as elites brasileiras influenciadas pela cultura cientificista e positivista europeia defendiam a aplicação de um projeto político modernizador para atrair os investimentos do mercado externo. O Rio de Janeiro, como capital do país, foi escolhido como seu espaço de implantação e portanto, modelo para o resto do país.

Esse espírito de modernização ao atingir o espaço físico carioca também redefiniu a forma que as pessoas viviam nele, em especial, as mulheres. O encarecimento do custo de vista da cidade e a eliminação das desvantagens do elemento feminino em relação a força física impulsionaram esse público a sair em busca de trabalho. A expansão do setor público e o aprimoramento do porto abriram novas oportunidades de emprego para elas. Por fim a construção de praças e espaços livres tornaram a cidade mais atrativa para o seu lazer criando novas formas de diversão como as festas e os bailes. Tudo isso acabou fazendo com que a mulher interagisse mais com o meio urbano.

Diante dessa maior liberdade, o governo brasileiro também desejava controlar o aspecto moral da população. Nesse sentido a família, em especial, a mulher tida como seu principal pilar, é vista como principal sustentáculo desse projeto normatizador. Com base na ideologia positivista, eles se apropriam das ideias de Lombroso para construir um modelo de como as mulheres deveriam ser, baseado na sua natureza frágil, dócil, inferior e destinada ao lar. Quem não se encaixava nesse padrão não era bem-visto cabendo ao esposo ou até mesmo a polícia a discipliná-la.

No caso Quitéria de Jesus, pode-se observar como os jornais expostos durante o trabalho estavam sendo influenciados pelas ideias positivistas debatidas pela elite dirigente. Em um primeiro momento, Quitéria foi interpretada como uma mulher de dupla natureza, criminosa e doméstica. Depois, ela já foi representada como uma pobre mãe presa devido ao seu amor ao marido e a sua falta de intelecto. Apesar de visões diferentes, ambas as interpretações reduziam o papel da mulher ao lar, seja para criticar quando ela se distancia dele, seja para despertar a atenção do público para com um problema. Havia portanto, um perfil do que é considerado o comportamento correto e honesto de uma mulher utilizado não só por advogados, como também pela imprensa (Abreu, 1989).

Essa repercussão pública sobre o seu inquérito pode ter ocorrido por algumas razões, Em primeiro lugar pode estar associada a uma tática dos jornalistas de vender periódicos devido a repercussão que um suposto erro da polícia e do judiciário causaria. Em segundo lugar, ela está associada ao próprio caráter do crime, como foi afirmado, dificilmente mulheres eram acusadas como rés de crime e posteriormente presas. Por fim existe a própria campanha realizada pelo Jornal do Comércio, periódico de grande importância na época, de que Quitéria, mesmo na sua condição de encarcerada, por ser uma mãe de um bebê branco e sem instrução formal, era incapaz de cometer o crime. 
Outra questão levantada durante a sua análise do caso é a distância da lei para a realidade. O caráter vago na letra da lei contribuiu para que o poder policial compeçasse a vagueza da lei ocasionando o aumento no número de prisões. A falta de estrutura e recursos impedia com que o que estava estabelecido nos regulamentos fosse aplicado na prática. A superlotação de detentos, a mistura de criminosos de diferentes modalidades e a coabitação de homens, menores e mulheres eram problemas presentes no seu espaço e despertavam a preocupação de intelectuais da época.

Também cabe destacar que prisão, mesmo sendo um ambiente que isola o detento do resto da sociedade, permanece em contato com o mundo exterior. No seu espaço eram reproduzidas as desigualdades que podem ser vistas na própria divisão dos detentos segundo o seu status social. Outra forma de contato mais direta era a visita de repórteres naquele espaço, como ocorreu no caso Quitéria de Jesus. Ao retratar as condições de cárcere dos criminosos, eles entretinham o público, levavam um pouco da cultura daquele ambiente e chamavam atenção para as condições desses estabelecimentos. A campanha de regulamentação das prisões ganhou força levando a primeira legislação nacional em 1940.Infelizmente, a baixa qualidade de acomodações do sistema carcerário é um problema que persiste e que vale a pena ser mais estudado.

\section{Referências}

Abreu, M. Meninas perdidas: o cotidiano do amor na Belle Époque. Paz e Terra

Ainda as notas falsas (1909). O Século, n.,p.3

Andrade, B. S. A. B (2018). Entre as leis da Ciência, do Estado e de Deus. O surgimento dos presídios femininos no Brasil. Tese de Doutorado. Universidade de São Paulo, São Paulo, SP, Brasil

As fábricas de dinheiro(1910). O Século, n.1125p.2

Até as mulheres (1909). A Capital, 2630, p.2

Bandeira, E. T. O. Relatório do Ministério da Justiça e Negociações Interiores. Rio de Janeiro: Imprensa Nacional,1909.

Barbosa, Marialva(2010). História cultural da imprensa Brasil-1900-2000. Rio de Janeiro: Mauad Editora Ltda,

Brasil. Decreto $\mathrm{n}^{\circ} 2110$ de 30 de setembro de 1909.Estabelece penas para os crimes de peculato, moeda falsa, falsificação de documentos e dá outras providências. https://www2.camara.leg.br/legin/fed/decret/1900-1909/decreto-2110-30-setembro-1909-580312-publicacaooriginal-103262-pl.html

Brasil. Decreto $\mathrm{n}^{\circ}$ 6.863, de 27 de fevereiro de 1908.Dá novo regulamento á Casa de Detenção do Distrito Federal. https://bd.camara.leg.br/bd/handle/bdcamara/18728

Brasil. Decreto $\mathrm{n}^{\circ} 6440$ de 30 de março de 1907. Dá novo regulamento ao serviço da Secretaria de Polícia do Distrito Federal. https://bd.camara.leg.br/bd/handle/bdcamara/18728

Brasil. Decreto no 847 de 11 de outubro de 1890 - De 11 de Outubro de 1890: Promulga o Código Penal. https://www2.camara.leg.br/legin/fed/decret/18241899/decreto847-11-outubro-1890-503086-publicacaooriginal-1pe.html.

Brasil. Lei $\mathrm{n}^{\circ}$ 1785, de 28 de novembro de 1907. Estabelece penas para o crime de peculato, e dá outras providências. https://www2.camara. leg.br/legin/fed/lei/1900-1909/lei-1785-28-novembro-1907-582576-publicacao original-105371-pl.html

Bretas, M. L(1997). Ordem na cidade: o exercício cotidiano da autoridade policial no Rio de Janeiro 1907-1930. Rocco

Bretas, M. L(2017). O que os olhos não veem: histórias das prisões no Rio de Janeiro. In: Maia, C.N, Neto F.S, Costa, M \& Bretas, M. L(orgs.). História das prisões no Brasil, 2. 185-194. Rocco

Bretas, M. L (2019). Guerra nas ruas. Gramma Editora

Chazkel, A (2017). "Uma perigosíssima lição: a Casa de Detenção do Rio de Janeiro na Primeira República”. In: Maia, C. N, Neto, F.S, Costa, M \& Bretas, M. L (orgs). História das Prisões no Brasil, 2, 5 a 14. Rocco

Crimes e criminosos (1910). Jornal do Comércio - Edição tarde. n.1136,p.1

De Araújo, R. M. B(1993). A vocação do prazer: a cidade e a família no Rio de Janeiro republicano. Rocco.

Galeano, D (2019). Fronteras del dinero falso: transacciones mercantiles y delito en el mundo atlántico. II Jornada Mercados en perspectiva histórica: consumos culturales e intercambios trasnacionales, Universidad Nacional de San Martín, Buenos Aires, Argentina.

Góes, L (2015). A" tradução" do paradigma etiológico de criminologia no Brasil: um diálogo entre Cesare Lombroso e Nina Rodrigues da perspectiva centro-margem. (Tese de Mestrado). Universidade Federal de Santa Catarina, Florianópolis, Santa Catarina, Brasil 
Research, Society and Development, v. 10, n. 8, e36610817357, 2021

(CC BY 4.0) | ISSN 2525-3409 | DOI: http://dx.doi.org/10.33448/rsd-v10i8.17357

Infeliz (1910). Jornal do Comércio - Edição Tarde. n.1101 36,p.1

Leal, C. E, \& Sandroni. Jornal do Comércio. In: Acervo CPDOC. CPDOC

Moedeiros falsos (1910). Jornal do Brasil, n.. 94,p.3

Movimento dos Tribunais (1909). O Paiz, n.9191,p.7

Os moedeiros falsos (1910). O Século, n. 1108.p.3

Ottoni, A V(2012). O Paraíso dos Ladrões: crime e criminosos nas reportagens policiais da imprensa (Rio de Janeiro, 1900-1920) (Tese de Doutorado). Universidade Federal Fluminense. Rio de Janeiro, RJ, Brasil.

Processo contra Quitéria de Jesus, n. Doc. 4546, 2a. Vara Federal, Arquivo da Justiça Federal do Rio de Janeiro, Rio de Janeiro, RJ, Brasil

Soihet, R(1989). Condição feminina e formas de violência: mulheres pobres e ordem urbana, 1890-1920(1ed). Rio de Janeiro: Forense Universitária.

Uma falsária(1909,maio,19). Gazeta de Notícias, n.136.,p.4;

Uma mulher que passa nota falsa(1909,maio,17). A Notícia, n. 110,p.1; 